\title{
Updates on HRF Payloads Operations in Columbus ATCS
}

\author{
Savino De Palo ${ }^{1}$ \\ Thales Alenia Space Italia, Strada Antica di Collegno 253, Turin, Italy, 10146 \\ Bruce D. Wright ${ }^{2}$ \\ The Boeing Company, Houston, Texas, 77058, USA \\ and \\ Robert E. Lake \\ NASA Marshall Space Flight Center, Huntsville, Alabama, 35812, U.S.A \\ Simon Challis ${ }^{4}$ \\ Astrium Space Transportation, Bremen, Germany \\ Robert Davenport ${ }^{5}$ \\ Astrium GmbH, Bremen, Germany \\ Donata Pietrafesa ${ }^{6}$ \\ Sofiter System Engineering, Corso Francia 35, Turin, Italy, 10138
}

\begin{abstract}
The NASA developed Human Research Facility 1 (HRF1) and Human Research Facility (HRF2) experiment racks have been operating in the European Space Agency (ESA) Columbus module of the International Space Station (ISS) since Summer 2008. The two racks are of the same design. Since the start of operations, unexpected pressure spikes were observed in the Columbus module's thermal-hydraulic system during the racks activation sequence. The root cause of these spikes was identified in the activation command sequence in the Rack Interface Controller (RIC), which controls the flow of thermal-hydraulic system fluid through the rack. A new Common RIC Software (CRS) release fixed the bug and was uploaded on both racks in late 2009. This paper gives a short introduction to the topic, describes the Columbus module countermeasures to mitigate the spikes, describes the ground validation test of the new software, and describes the flight checks performed before and after the final upload. Finally, the new on-orbit test designed to further simplify the racks hydraulic management is presented.
\end{abstract}

\footnotetext{
${ }^{1}$ Thermal Engineer, BS-SIT, ThalesAlenia Space, Strada Antica di Collegno, 246 Torino - Italy/10146

${ }^{2}$ International Integration Lead Engineer, Payload Engineering \& Integration, The Boeing Company, 13100 Space Center Boulevard, MS HB3-10, Houston, TX, 77059-3607

${ }^{3}$ NASA Flight System Engineer, MSFC-ES11

${ }^{4}$ Columbus Flight Director, TO47, PO Box 286156 - 28361 Bremen - Germany

${ }^{5}$ Payload, IOT Payload Engineering Integration, Astrium GmbH, Airbus Allee 1, 28199 Bremen, Germany

${ }^{6}$ Thermal Engineer, Sofiter System Engineering, e-mail: donata.pietrafesa@external. thalesaleniaspace.com.
} 


\section{Nomenclature}

$\begin{array}{ll}\text { ATCS } & =\text { Active Thermal Control System } \\ C R S & =\text { Common RIC Software } \\ E S A & =\text { European Space Agency } \\ \text { FGSE } & =\text { Fluidic Ground Support Equipment } \\ I S S & =\text { International Space Station } \\ M S F C & =\text { Marshall Space Flight Center } \\ P R C U & =\text { Payload Rack Checkout Unit } \\ \text { RFCA } & =\text { Rack Flow Control Assembly } \\ \text { RIC } & =\text { Rack Interface Controller } \\ \text { SFCA } & =\text { System Flow Control Assembly }\end{array}$

\section{Introduction}

$\mathrm{T}$ HE two Human Research Facilities HRF1 and HRF2 are two NASA experiment racks operating in Columbus, the ESA laboratory on the ISS since Summer 2008. The HRF1 one rack was the first research facility on the ISS and has been operating successfully on-orbit since March of 2001. HRF2 was delivered to orbit on a later flight and both racks were transferred to the Columbus module shortly after the module was commissioned on-orbit.

The design and science objectives of these two racks are discussed in detail in two previous papers $[1,2]$. It is summarized here again.

A number of NASA facilities are designed around the concept of providing a set of common interfaces for small, modular experiments. This allows research objectives to change over time and for the common packaging of experiments. This is the concept behind the NASA EXPRESS racks. Several middeck and 2 SIR drawer slots are available in each EXPRESS rack. There are currently eight EXPRESS racks onorbit in the US Laboratory, the European Columbus module and the Japanese Experiment Module.

The design of the EXPRESS rack was extended to a few other research facilities; the Window Observation Research Facility (WORF), the Habitat Holding Racks (HHR), and the two HRF racks. The HHR was part of the Centrifuge Facility planned for the ISS, but the project was cancelled and the Centrifuge Facility was never completed. These other facilities are sometimes referred to as "EXPRESS derivatives".

The HHR and EXPRESS racks share common design features. The thermal control system in each rack has three internal flow controllers that use a modulated solenoid valve, flow meter and a dedicated PID controller. The RIC controls the flow of water by

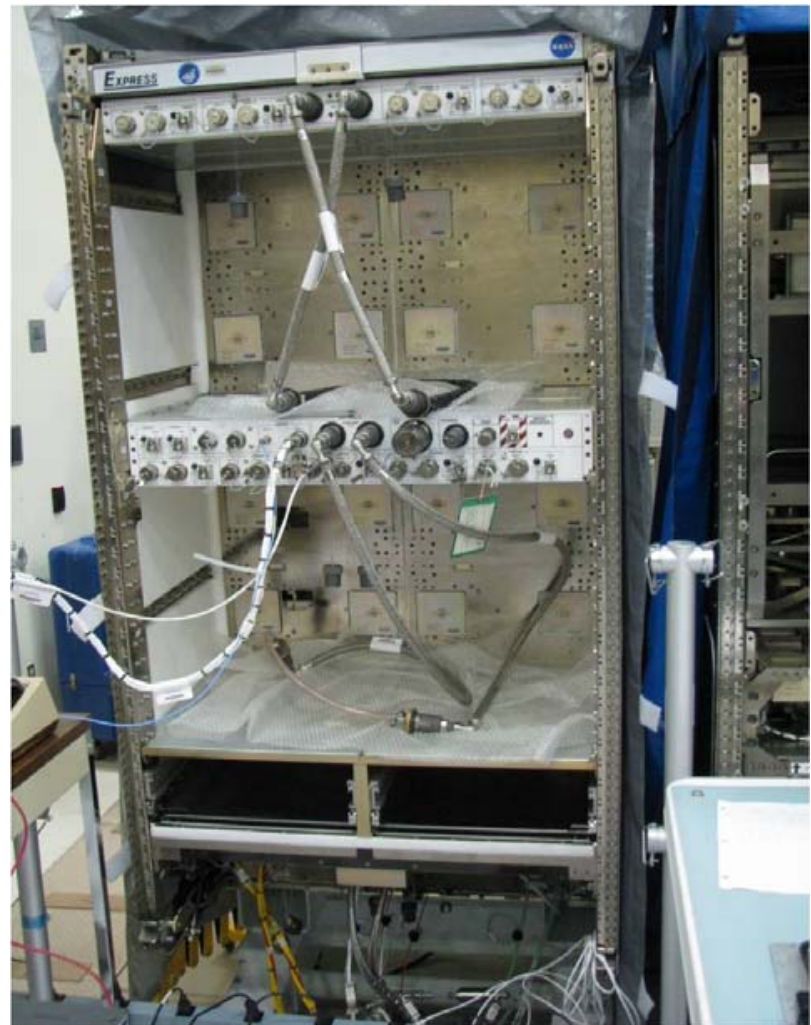

Figure 1. EXPRESS Rack 8 providing a voltage to the flow controller and the flow meter provides a signal back to the RIC which is downlinked in the rack's Health and Status data. One of the active flow controllers is a normally open valve and controls the flow of cooling water to the rack subsystems. The other two controllers are normally closed valves that control the flow of cooling water to two legs of the flow system supporting the experiments.

The common design features of the HRF and EXPRESS racks mean that the RIC software for all of the EXPRESS and EXPRESS derivative is also common. The Common RIC Software (CRS) is sustained by the EXPRESS Program at Marshall Space Flight Center and is developed and tested in the software and hardware test 
facilities there. The EXPRESS Rack 3 is also located in the Columbus module and shares the same CRS as the HRF racks.

ESA and NASA have an extensive history of operation of the HRF racks in Columbus that began with ground testing of a HRF prototype rack in the Columbus module in Bremen. The results of this ground testing led to the implementation of start-up and shut-down procedures to minimize potential of a water hammer in the Columbus ATCS that can occur if the solenoid valve is allowed to suddenly close. The RIC software also contains an algorithm to slow the transition from one flow rate to another. After operations of the HRF racks and EXPRESS Rack 3 began in Columbus, the Columbus operations team noticed that during startup and shutdown of the HRF racks there were pressure spike noted in the Columbus ATCS. An Anomaly Resolution Team (ART) was convened with participation from both ESA and NASA teams to determine the cause of the pressure spikes and to find a resolution.

The HRF racks were allowed to continue science operations during this time, but special steps were put in place during the startup of the racks. The WFSV for each rack was modulated to miminize the flow and pressure differential across the rack's ATCS interface to minimize the pressure spikes. The pressure spikes on shutdown were resolved by changing the shutdown procedure for the racks.

The ART determined that the pressure spikes during startup were caused by the power on sequence of components in the racks. The CRS at the time was powering the system flow control valve, and then sending a signal to the valve to be in the normally open position. This allowed the initial flow rate signal from the RIC to be in an initial intermediate state, and the valve would move to an initial intermediate position. It would then receive the signal to open fully. These two transitions occurred rapidly and caused the pressure spike in the system.

The CRS was modified to first send the flow rate signal to command the valve fully open, and then power on the valve and flow controller. Ground tests were then conducted to ensure the desired result was obtained prior to updating the on-orbit software. The ground test results and on-orbit results are described below.

\section{CRS5 to CRS6 Ground Test Validation}

The new CRS release (CRS6) with the bug fix was designed and verified at Software Test Bed at Boeing premises on mid 2009 and tested at rack level using the Express Flight Rack 8 (Figure 1) at NASA-MSFC. The major test objective was to verify the absence of pressure spike during rack activation and deactivation when the thermal flow control algorithm is not active. Same set-up was run with CRS5 to further confirm the control algorithm improvement.

\section{A. Test Set-Up}

The FGSE adopted for the ER8-CRS6 test was the Payload Rack Checkout Unit (PRCU) the functional hydraulic layout of the test set-up is shown in Figure 2. 


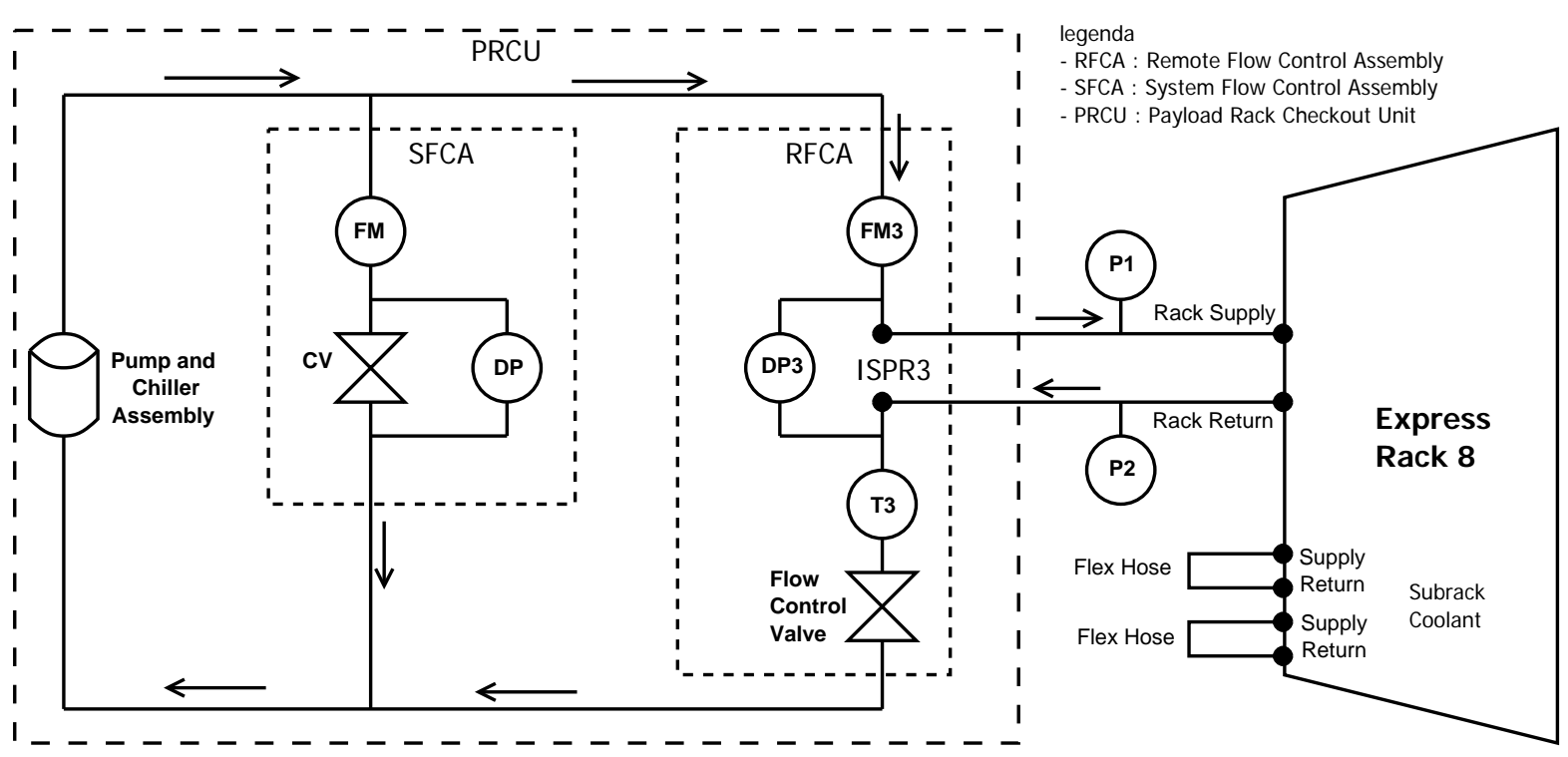

Figure 2. ER8 and PRCU test set-up functional layout

PRCU provides ISS I/F simulation and was already used by NASA to verify interface requirements of pressurized payloads to be installed on board ISS $^{3}$. In particular, the PRCU is a ground simulator of the US Lab Internal Temperature Control System (ITCS) and is therefore different to the Columbus Active Thermal Control System (ATCS) for the following reasons:

- PRCU pressure drop control works with a System Flow Control Assembly (SFCA) subsystem that controls the plenum pressure drop by changing the stroke of the plenum by-pass, i.e., the SFCA internal control valve (CV in Figure 2). The PRCU pump works at constant speed.

Columbus ATCS does not have any equivalent SFCA assembly and the plenum pressure drop is guided by changing the ATCS pump speed

- The SFCA set point of nominally 13 PSI, is more than twice the Columbus set-point of 6.1 PSI

- The Rack flow Control Assembly (RFCA) has an internal active control loop, while the equivalent Columbus valve, the Water Flow Selection valve (WFSV) does not. For this test (and on orbit in the US Lab), the RFCA was not in active control mode when the rack was working: the RFCA valve was set prior to ER8 activation to a certain flow rate and then blocked to that position with feedback control deactivated.

For this test ER8 was equipped with two flex hoses, thus enabling thus the flow through the two subsystem legs and the intervention of relevant hydraulic control systems. Flow and pressure drop measurements from SFCA, RFCA and internal flow meters were a sampled with a frequency of $1 \mathrm{~Hz}$. Additional pressure sensors P1 and P2 that measured the supply and return pressure respectively (Figure 2), were introduced to catch spike events; data were acquired at a frequency of $100 \mathrm{~Hz}$. 
All tests performed are summarized in the Table 1

\begin{tabular}{|c|c|c|c|c|c|c|c|}
\hline \multirow{2}{*}{ Case } & \multirow{2}{*}{ CRS } & \multirow{2}{*}{ Date } & \multicolumn{2}{|c|}{ SFCA } & \multicolumn{2}{c|}{ RFCA } & \multirow{2}{*}{ Note } \\
\cline { 4 - 7 } & & & $(\mathrm{PSI})$ & $(\mathrm{kPa})$ & $(\mathrm{Lbs} / \mathrm{h})$ & $(\mathrm{Kg} / \mathrm{h})$ & \\
\hline- & 5 & $15-$-Oct-2009 & 13 & 89.6 & 225 & 102 & US Lab $\Delta \mathrm{P}$ \\
\hline $\mathrm{A}$ & 6 & 20-Oct-2009 & 13 & 89.6 & 225 & 102 & US Lab $\Delta \mathrm{P}$ \\
\hline $\mathrm{B}$ & 6 & 20-Oct-2009 & 13 & 89.6 & 225 & 102 & US Lab $\Delta \mathrm{P}$ \\
\hline C & 6 & 20-Oct-2009 & 13 & 89.6 & 157 & 71 & US Lab $\Delta \mathrm{P}$ \\
\hline $\mathrm{D}$ & 6 & 20-Oct-2009 & 13 & 89.6 & 157 & 71 & US Lab $\Delta \mathrm{P}$ \\
\hline A1 & 6 & 6-Nov-2009 & 6.1 & 42 & 157 & 71 & Columbus $\Delta \mathrm{P}$ \\
\hline B1 & 6 & 6-Nov-2009 & 6.1 & 42 & 220 & 100 & Columbus $\Delta \mathrm{P}$ \\
\hline C1 & 6 & 6-Nov-2009 & 6.1 & 42 & 220 & 100 & Power removal \\
\hline
\end{tabular}

Table 1. ER8-PRCU Tests Cases

\section{B. CRS5 Test Results}
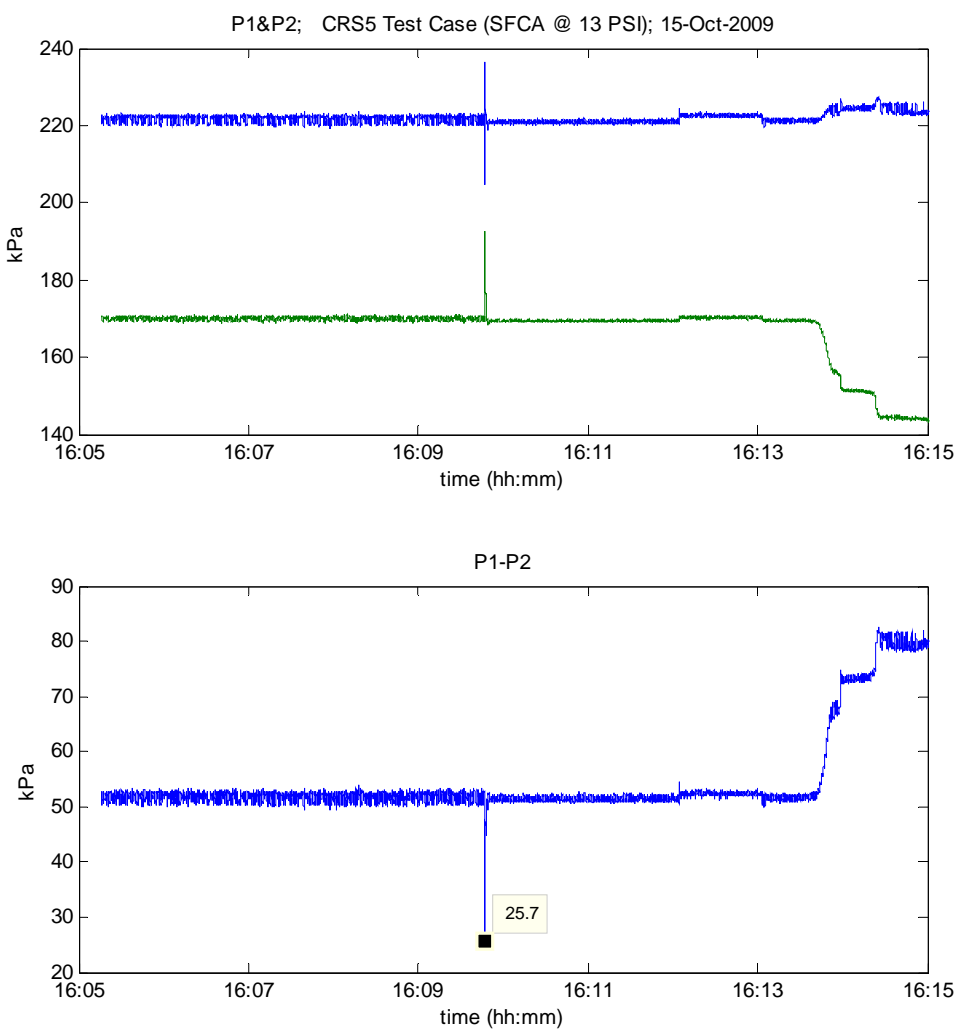

First test was performed with CRS5 software to confirm the presence of spikes during activation for the hardware configuration selected. Test was configured with SFCA at 13 PSI $(\sim 90 \mathrm{kPa})$ and RFCA set to provide an initial flow (i.e., with ER8 unpowered) of about $225 \mathrm{lbs} / \mathrm{hr}(\sim 102 \mathrm{Kg} / \mathrm{h})$.

In Figure 3 are shown the Dewetron P1\&P2 data (first plot) and their difference (second plot), from rack power on until completion of the start-up sequence. The activation spike at $25.7 \mathrm{kPa}$ is clearly visible, thus confirming the validity of the test set-up adopted.

Figure 3. ER8-PRCU with CRS5 test data 


\section{CRS6 Test Results with SFCA at 13 PSI}
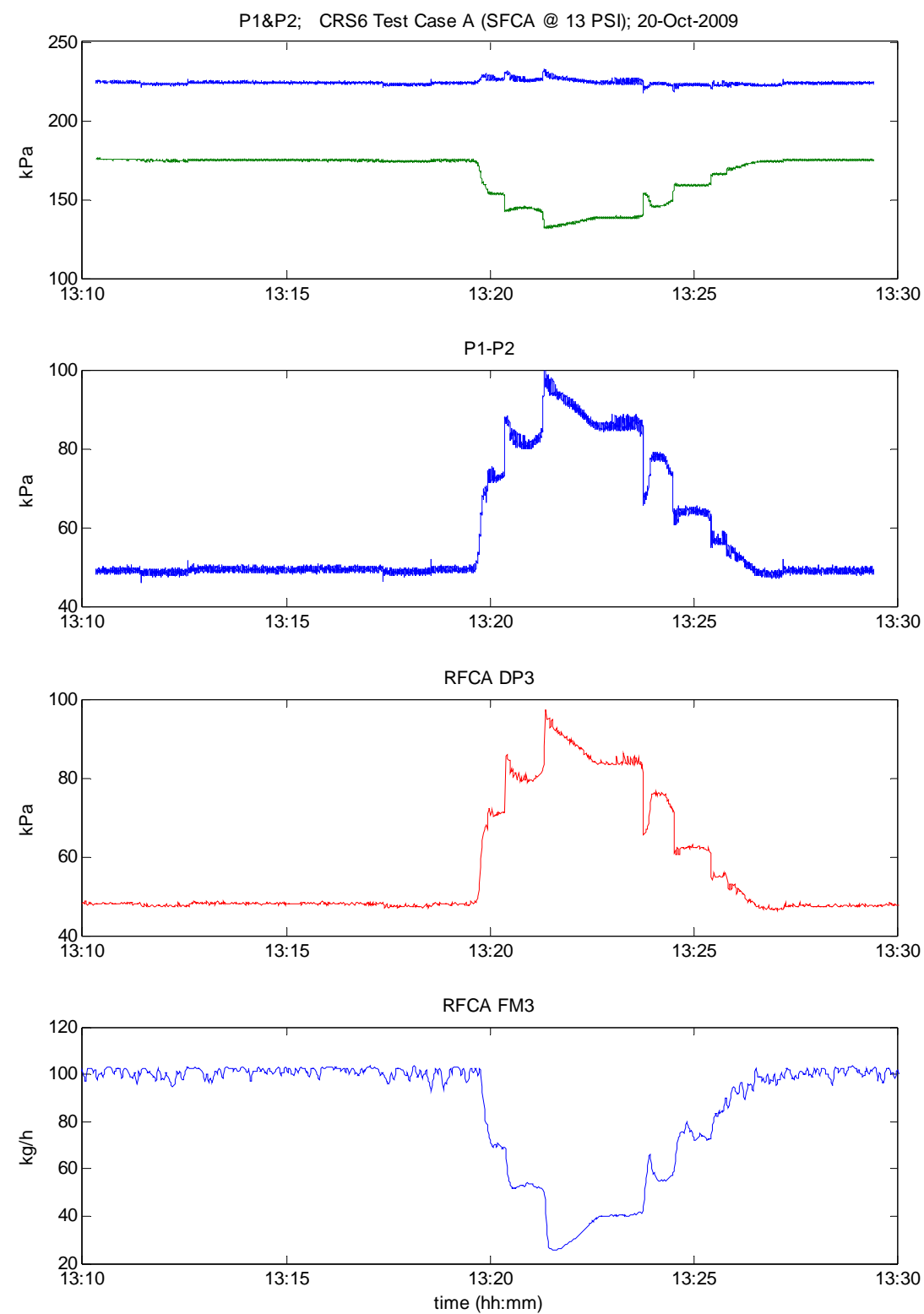

Figure 4. ER8 test data with CRS6 and SFCA at 13 PSI (Case A)

First 4 tests with new CRS6 were performed with SFCA set as working in the US Lab, i.e., with a set point of 13 PSI.

The first two tests (cases A\&B in Table 1) had the RFCA configured to provide $225 \mathrm{lbs} / \mathrm{hr}$ $(102 \mathrm{Kg} / \mathrm{hr})$ to ER8, followed then by two other tests (cases C\&D in Table 1) with RFCA configured to provide $157 \mathrm{lbs} / \mathrm{hr}$ $(71 \mathrm{Kg} / \mathrm{hr})$ to ER8.

For all cases the rack started from power-off position with avionic leg fully open and the sub-systems legs fully closed. Once the rack was turned on, it went through the start-up sequence, with the avionic valve from fully open to the flow setpoint, approximately $45 \mathrm{~kg} / \mathrm{hr}$.

The $\mathrm{P} / \mathrm{Ls}$ legs were not commanded open at any point during these 4 flow testing. Before rack shut down, the avionic valve was commanded back to fully open position as for current flight operations.

Figure 4 shows four plots of the test case A, comprising (starting from top) as follows: pressure sensors reading $\mathrm{P} 1$ and P2 ( $1^{\text {st }}$ plot $)$, rack pressure drop P1-P2 (2 $2^{\text {nd }}$ plot), RFCA DP3 $\Delta$ P measurement $\left(3^{\text {rd }}\right.$ plot) and RFCA FM3 flow rate measurement $\left(4^{\text {th }}\right.$ plot $)$.

All plots cover the activation and deactivation of the rack. No ER8 (internal flow) and SFCA data were retrieved for these cases.

For this case, as for the other three cases tested at 13 PSI, no activation/deactivation spikes were measured: first CRS6 test day was thus performed successfully, giving the go for next tests to be performed. 


\section{CRS6 Test Results with SFCA at 6.1 PSI}
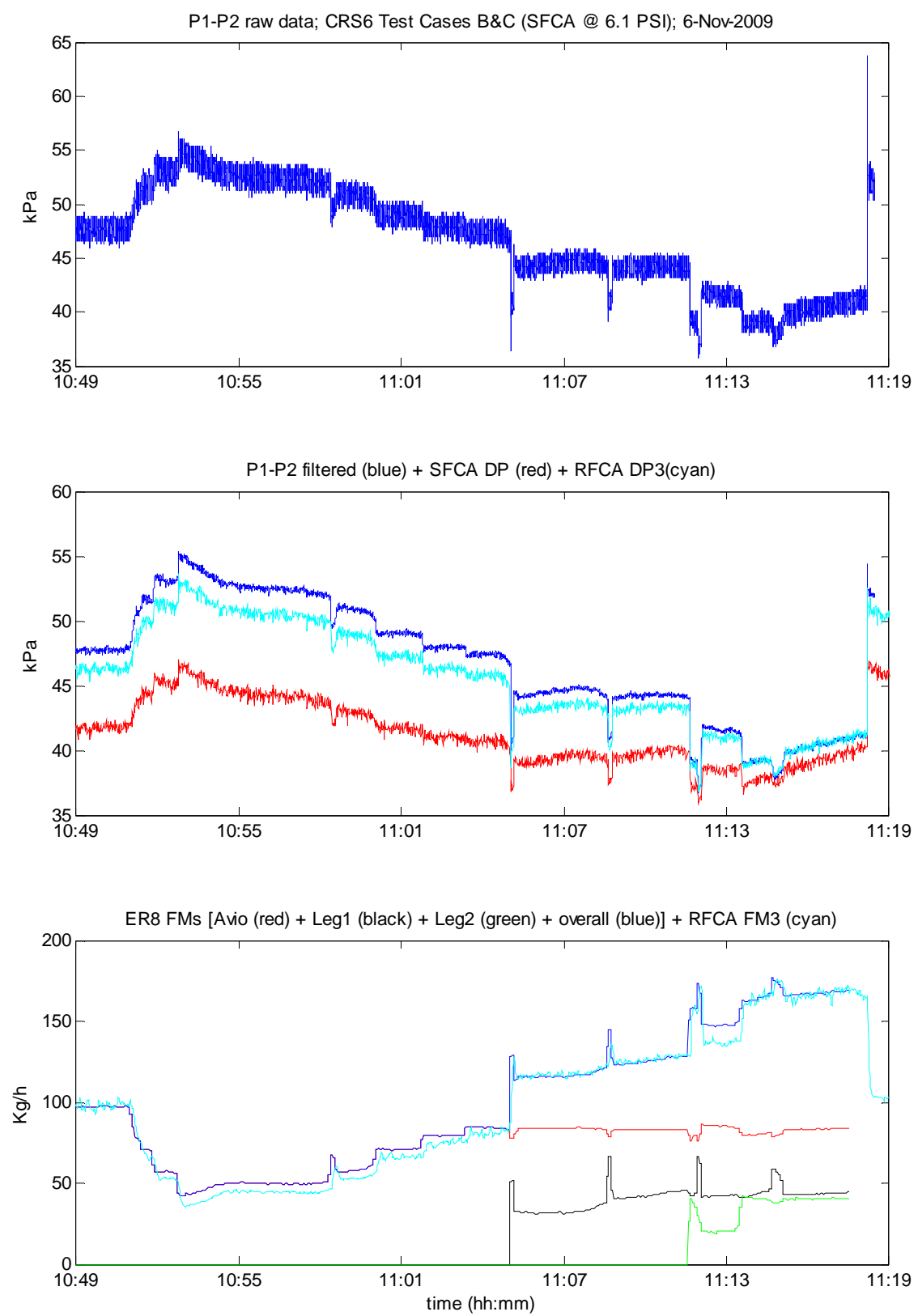

Figure 5. ER8 test data with CRS6 and SFCA at 6.1 PSI (Cases B+C)

Additional tests were performed few weeks later, with SFCA set point reduced from 13 PSI to 6.1 PSI, as applicable for the Columbus plenum pressure drop, and in particular:

- Start up and shutdown with RFCA configured to provide $157 \mathrm{lbs} / \mathrm{hr} \quad(71$ $\mathrm{Kg} / \mathrm{hr}$ ) to ER8. This case is to be compared with cases C\&D performed at 13 PSI, for which the only difference is in the SFCA set-point (case A1 in Table 1)

- Start up with RFCA full open. In this configuration with the rack off, the flow through the rack was approximately $220 \quad \mathrm{lbs} / \mathrm{hr}$ (100 Kg/hr). This case was selected in order to have a worst case condition, i.e., simulating the WFSV fully open condition (case B1 in Table 1)

- After completion of start up in test B1, the rack was configured directly for full flow by first setting the subsystem/avionics valve to $180 \mathrm{lbs} / \mathrm{hr}(82 \mathrm{Kg} / \mathrm{hr})$, then setting payload leg 1 to 100 $\mathrm{lbs} / \mathrm{hr}$ (45 $\mathrm{Kg} / \mathrm{hr})$, and finally setting payload leg 2 to $100 \mathrm{lbs} / \mathrm{hr}(45 \mathrm{Kg} / \mathrm{hr})$ for a total flow through the rack of approximately $380 \mathrm{lbs} / \mathrm{hr}$ (172 Kg/hr). At this configuration power was then removed from the rack to record the water spike/hammer event (case C1 on Table 1). Aim of last test was not to verify the CRS6 itself, but to measure the difference between the SFCA pressure spike, corresponding to the telemetry pressure drop data and the pressure peak measured by P1\&P2 sensors, acquired with higher sampling rate. This data was useful to extrapolate the real pressure stress acting on Columbus Delta Pressure Sensor Block (DPSB) when EXPRESS racks power removal occurs.

For this test day also SFCA and ER8 data were retrieved. In Figure 5 are reported three plots of the test cases B1 and $\mathrm{C} 1$, composed (starting from top) as follow: $\Delta \mathrm{P}=\mathrm{P} 1-\mathrm{P} 2$ raw data as acquired with a sampling rate of $100 \mathrm{~Hz}$ (1st plot), $\triangle \mathrm{P}$ filtered (blue line) to reduce noise and compared with RFCA DP3 $\triangle \mathrm{P}$ (cyan line) and SFCA DP (red 
line) measurements, acquired with a sampling rate of $1 \mathrm{~Hz}$ (2nd plot) and RFCA FM3 flow rate measurement (cyan line) vs ER8 legs and overall flow rates (3rd plot), with a sampling rate of $1 \mathrm{~Hz}$.

Major outcome is that for the nominal activations, no spike were observed also on this test day, showing that CRS6 fix was properly designed and implemented and no impacts expected depending on the working $\mathrm{SFCA} /$ plenum $\triangle \mathrm{P}$ set-point. Based on this result, the go for CRS6 $\mathrm{S} / \mathrm{W}$ upload in orbit was given.

\section{Flight Telemetry Data}

After successful completion of ground tests, the CRS6 was uploaded on-orbit on HRF1 and HRF2 in late October 2009. In the following flight telemetry of last activation with CRS5 and first activation with CRS6 for the HRF1 are shown to highlight software improvement benefits. For each activation three plots provide overview and details on activation, showing the most relevant data, both from Columbus and HRFs side, and in particular:

Plot 1. WFSV position (opening \%)

Plot 2. WPA Flow rate $(\mathrm{Kg} / \mathrm{h})$ - this value is filtered to reduce noise

Plot 3. DPSB $\triangle \mathrm{P}(\mathrm{kPa})$

Plot 4. HRF partial and overall flow rates

\section{E. DOY 300/2009 HRF1 Activation with CRS5}
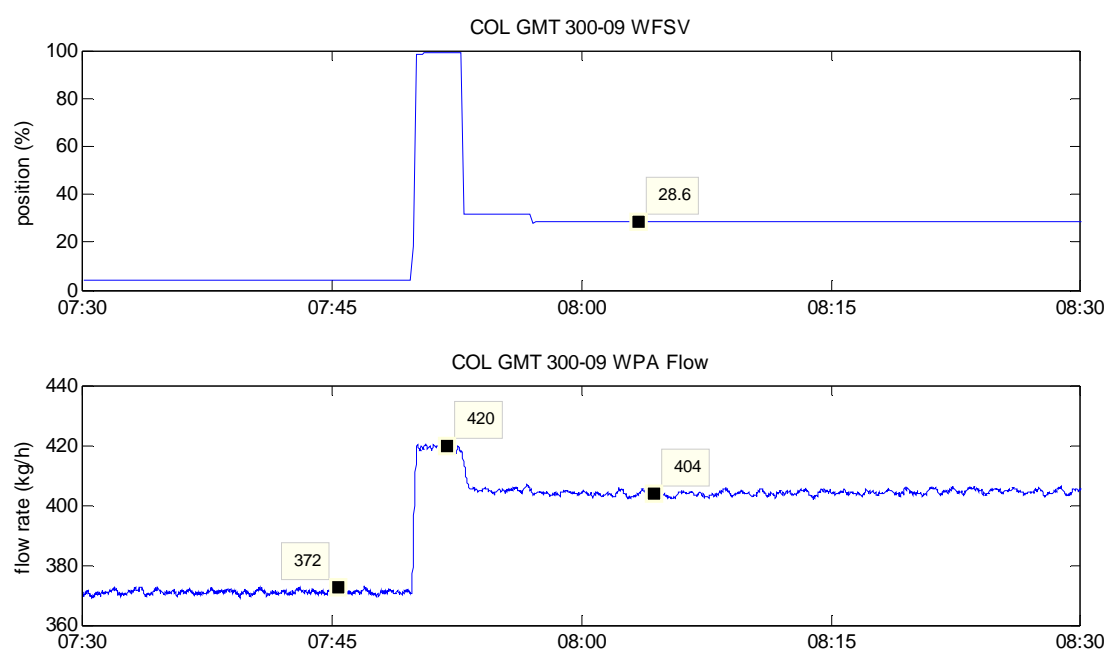

Last HRF1 activation with CRS5 installed was performed at DOY 300/2009. Columbus water loop configuration was with initial pump flow rate of about $370 \mathrm{~kg} / \mathrm{h}$, due to MSG rack. WFSV was fully opened bringing the pump flow rate up to $420 \mathrm{~kg} / \mathrm{h}$ and then partially closed down to about $28.5 \%$.

Pressure spikes due to WSFV opening/closure were $38.6 \mathrm{kPa}$ and $44.6 \mathrm{kPa}$ respectively. HRF1 activation produced a small spike of 41.1 $\mathrm{kPa}$, due to CRS5 $\mathrm{S} / \mathrm{W}$ still in

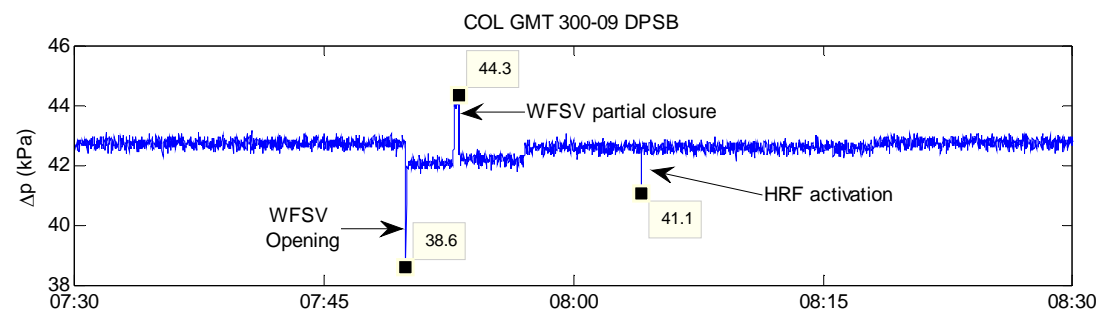
place. This spike was within the control dead band thanks to graceful activation sequence which was still in place.

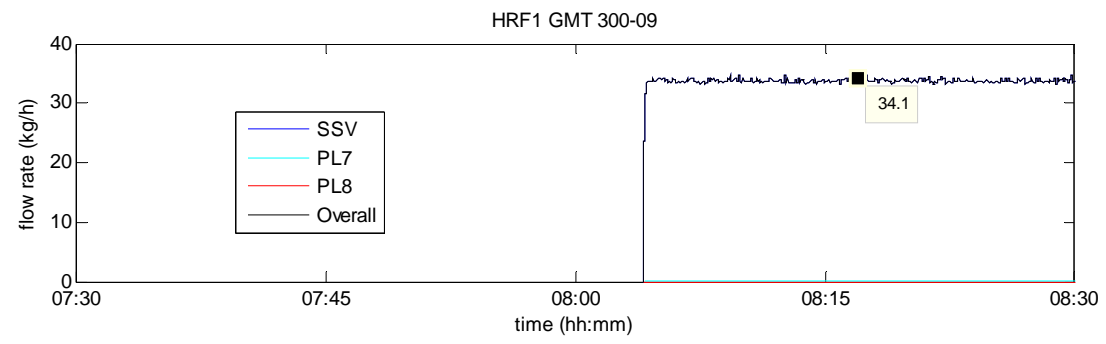

Figure 6. - HRF1 Activation with CRS5

American Institute of Aeronautics and Astronautics 


\section{F. DOY 306/2009 HRF1 Activation with CRS6}
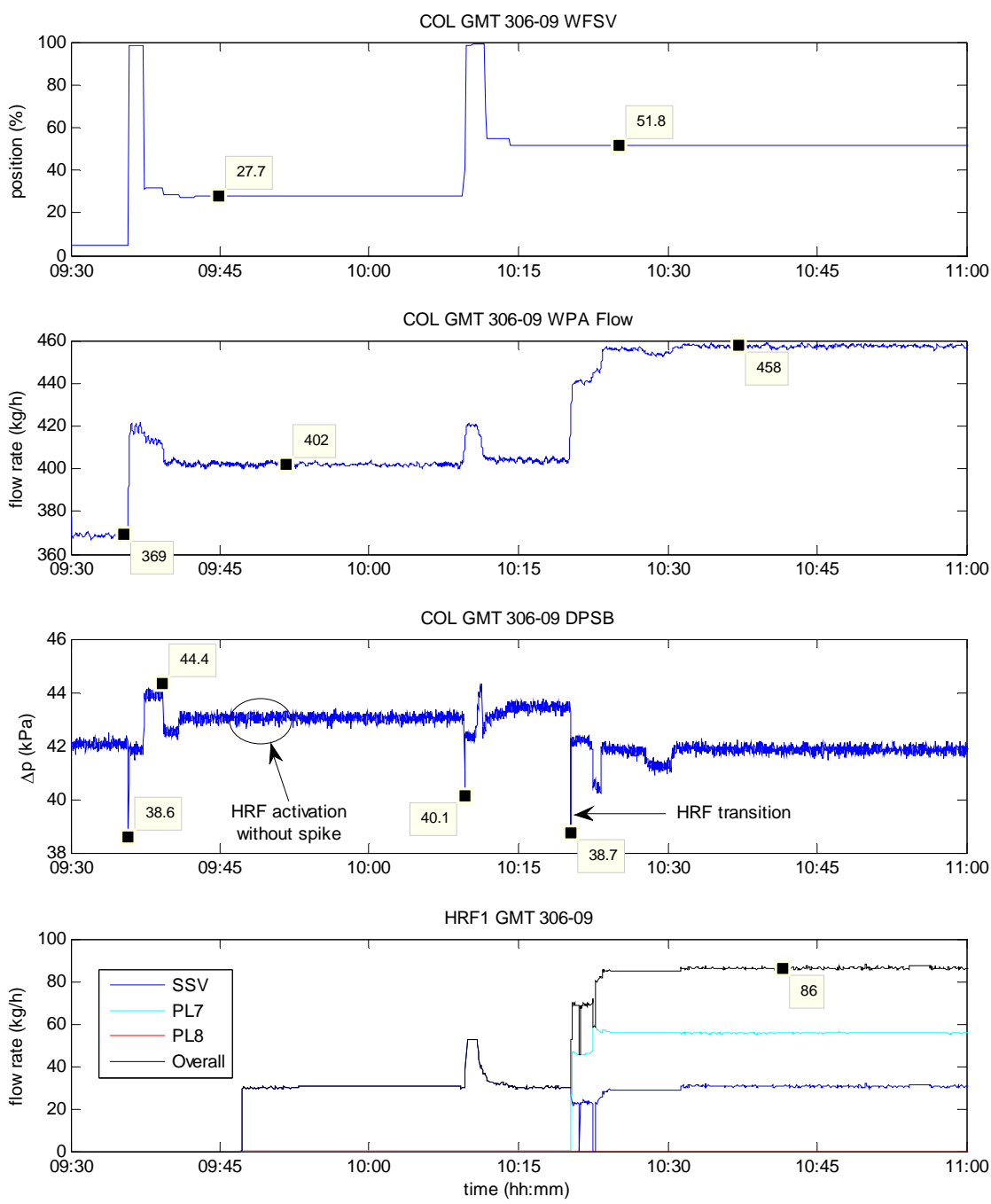

The first activation of HRF1 with the CRS6 installed was performed on DOY 306/2009

A for DOY300, WFSV prepositioning for rack activation produced spikes from $38.6 \mathrm{kPa}$ to $44.4 \mathrm{kPa}$, while with respect GMT300 no pressure spike was measured at DPSB level during HRF 1 activation, confirming the expected behavior of the rack with the new control $\mathrm{S} / \mathrm{W}$.

After activation the WFSV stroke was adjusted to $51.8 \%$ and HRF reconfigured producing a low peak at 38.7 $\mathrm{kPa}$. The rack overall flow of 86 $\mathrm{kg} / \mathrm{h}$ was in line with expected figure.

Same comparison was performed on HRF2 activations, showing the same behavior of HRF1.

Nominal activation sequence for the HRF racks was then restored after about one year, with WFSV valves opening increased to $32 \%$ and $38 \%$ respectively for HRF1 and HRF2.

Figure 7. - HRF1 Activation with CRS6

\section{Next HRF On-Orbit Tests}

Each HRF P/L has five different working configurations, with corresponding valves settings, named Thermal Cases labeled from $\mathrm{A}$ to $\mathrm{E}$, where $\mathrm{A}$ is the start-up configuration and $\mathrm{E}$ the most demanding flow.

Before any transition between Thermal Cases, the stroke of the upstream Columbus WFSV must be set to a predefined position, depending on Thermal Case selected. WFSV setting was originally conceived to provide a more stable configuration for rack internal valves, as derived from ground compatibility test ${ }^{1}$, limiting also the flow rate through the rack in case of rack transient or failure when all HRF valves are in fully open configuration.

After CRS6 upgrade, it is proposed to verify on-orbit the real need of intermediate WFSV positions, by testing the dynamic of HRF1 and HRF2 working with incremental WFSVs openings, up to an enveloping position that can allow an independent management of the Thermal Cases from P/Ls side but at the same time compliant with the rack flow rate limitation of $190 \mathrm{~kg} / \mathrm{h}$. Other advantages of having only one WFSV opening is the reduction of pressure spikes due to WFSV movements itself. 


\section{Conclusion}

The Common RIC Software, version CRS5, controlling the rack activation sequence in the HRF1 and HRF2 operating in the European Space Agency (ESA) Columbus module since early 2008, was identified as the cause of unexpected pressure spikes observed in the thermal-hydraulic system. An upgraded CRS6 software version, which changed the rack activation sequence, was first successfully ground tested in a Software Test Bed facility and then in the Payload Rack Checkout Unit (PRCU) at NASA-MSFC using the Express Flight Rack 8 as test rack. No unexpected pressure spikes were observed for both the PRCU Rack Flow Control Assembly (RFCA) set point of 13 PSI as in the US Lab, or 6.1 PSI for the applicable plenum pressure drop in Columbus (even with worst case condition of RFCA fully open prior to rack activation to simulate Columbus Water Flow Selection Valve (WFSV) fully open).

The CRS6 software was uploaded to the HRF1 and HRF2 racks in October 2009. Subsequent in-orbit testing for HRF1 activation produced pressure spikes of $38.6 \mathrm{kPa}$ and 44.4.kPa: no pressure spike was observed at the Delta Pressure Sensor Block level confirming the expected behavior of the CRS6 rack control software. Subsequent adjustment of the relevant WFSV to $51.8 \%$ open, produced only a low peak of $38.7 \mathrm{kPa}$. Similar behavior was observed for HRF2.

The successful on-orbit testing of the CRS6 rack control software led to nominal rack activation being restored with WFSV valve opening set to $32 \%$ and $38 \%$ for HRF1 and HRF2 respectively. Future testing is proposed to identify an enveloping setting of the WFSV that allows independent control of the five HRF thermal cases while concurrently limiting the rack flow rate to the maximum allowed $190 \mathrm{~kg} / \mathrm{h}$. Use of a unique WFSV setting for all rack thermal cases will also reduce pressure spikes induced by the WFSV movement.

The investigation, countermeasure development and implementation, and resolution of the delta pressure sensor spike problem detailed in this paper, was a milestone moment for Integrated Space Station Operations, since this was the first time ESA and NASA Engineering and Operations teams have worked so closely together to resolve an in-orbit anomaly impacting both the ESA Columbus Module and NASA Payload Operations.

Through the close and successful cooperation of the various European and American teams it was possible to continue operations via an agreed countermeasure (workaround) strategy at an early stage of the problem investigation and also overcome the technical challenges of using a space station thermal loop test set up not originally designed to represent Columbus, to demonstrate effectively the software solution to the problem before uplinking and implementing it in-orbit.

What is more the cooperative work that has been put into addressing the anomaly has fostered a positive environment which has lead not only to the resolution of the original problem but also the commitment to optimize HRF Payload Operations in the future, through proposed further in-orbit testing.

It is hoped by the authors, that through the experience that has been gained by ESA and NASA in working together to resolve the delta pressure spike anomaly (the details of which are reflected in this paper), a good working basis has been achieved for facing future technical challenges in the effort to support continued successful NASA Payload Operations in Columbus.

\section{References}

${ }^{1}$ S. De Palo, B. D. Wright, B. G. Rhone, Z. Szigetvari, S. Hinderer, J. Persson, "Columbus to Human Research Facility Hydraulic Compatibility Test Analysis and Results", Proceedings of $35^{\text {th }}$ ICES Conference, SAE, 2005

${ }^{2}$ S. De Palo, R. Passini, A. Quaranta, B.D. Wright, "Columbus Thermal Hydraulic Operations with US Payloads", Proceedings of $39^{\text {th }}$ ICES Conference, SAE, 2009.

${ }^{3}$ SSP 57000, "Pressurized Payloads interface Requirements Document - International Space Station Program"

${ }^{4}$ A. Quaranta, G. Bufano, S. De Palo, S. Hinderer, J. M. Holt, S. Palumberi, "Columbus Payloads Flow Rate Anomalies", Proceedings of $41^{\text {st }}$ ICES Conference, AIAA-SAE, 2011. 